\title{
Hybrid Customer Interaction
}

\author{
Rebecca Nüesch · Rainer Alt • Thomas Puschmann
}

Received: 10 October 2014/Accepted: 11 November 2014/Published online: 7 February 2015

(C) Springer Fachmedien Wiesbaden 2015

Keywords Customer interaction · Convergence · Channel management $\cdot$ Banking

\section{Drivers and Potentials}

\subsection{Convergence as Enabler}

The increasing fusion of the digital and the physical world leads to new ways of customer interaction (Leimeister et al. 2014), induced by technology convergence, such as smart phones, tablet PCs and the social web (Brenner et al. 2014). For instance, customers walk down a shopping mall, utilizing their smart phone cameras to browse through available offers for products they just saw in the nearby shops. In this well-known hybrid customer interaction scenario customers are simultaneously present both in the physical world of the shopping mall and in the digital world of the mobile internet (Heinemann 2013). Technological progress

Accepted after one revision by Prof. Dr. Sinz.

R. Nüesch

Institute of Information Management, University of St. Gallen, Müller-Friedberg Str. 8, 9000 St. Gallen, Switzerland

e-mail: rebecca.nueesch@unisg.ch

Prof. Dr. R. Alt

Information Systems Institute, University of Leipzig,

Grimmaische Str. 12, 04109 Leipzig, Germany

e-mail: rainer.alt@uni-leipzig.de

Dr. T. Puschmann ( $₫)$

Business Engineering Institute St. Gallen, Lukasstrasse 4,

9008 St. Gallen, Switzerland

e-mail: thomas.puschmann@bei-sg.ch and changed customer behavior, particularly the simultaneous use of multiple media, thus result in "channel hopping" (Heinemann 2013, p. 18).

Especially mobile-commerce is a key factor for this convergence, as it enables the fusion of online and offline channels. This channel convergence replaces a clear separation of electronic channels (media-supported, e.g., the internet), stationary channels (e.g., local branches), and mobile channels (e.g., field service) (e.g., Neslin and Shankar 2009). Businesses offering their products and services in this setting face the challenge of redesigning their organizational structures through a customer-driven configuration of value chains to provide interaction channels, processes and systems as a "seamless system from a single source", referred to as "no-line systems" (Heinemann 2013, p. 3). The goal is to cope with a maximum convergence of interaction channels and technologies enabling hybrid and seamless customer interaction (Bettiga et al. 2013, p. 179). Additionally, from a strategic perspective the merging of channels also implies a process convergence which describes customers' processes and companies' CRM processes integration for the delivery of services across different channels and technologies. Customers are increasingly becoming part of these processes and have the option to obtain time- and location-independent services.

Thus, hybrid customer interaction takes place on three levels: strategy (channel convergence), processes (process convergence) and systems (technology convergence). It addresses the convergence on those levels and influences their design from a company's perspective (Bettiga et al. 2013). Designing no-line systems is a prerequisite for hybrid customer interaction and requires the modification of business models, processes and systems. 


\subsection{Example and Potentials from the Banking Industry}

Convergence and changing customer behavior are currently leading to a transformation of the banking industry. Decreasing physical branch visits and intensified use of electronic channels forces many banks to change their business models towards hybrid customer interaction.

The example of a Swiss universal bank offering retail, private banking and commercial banking services illustrates the challenges of implementing hybrid customer interaction. At present, the bank operates a branch network with more than 80 locations and maintains more than 300 ATMs. Transaction processes are provided by an online banking system and support processes via a call center. All of these channels were formerly organized as separate business units and operated on different systems and data.

In order to enable hybrid customer interaction, the bank had to redesign its customer contact strategy, organization and IT systems. From a strategic point of view, the channels were positioned as equally important customer contact points. Branches were extended by means of $24 \mathrm{~h}$ selfservice terminals and multi-touch advisory functionalities. Advisors' competencies were strengthened by using tablet PCs in customer-related advisory processes instead of paper-based forms (Nueesch et al. 2014). Furthermore, the website and online banking portal were complemented by new self-services (e.g., personal finance management) allowing customers to plan and organize their financial resources.

In order to implement this hybrid customer interaction strategy, the bank changed its organization and implemented new processes. While in the past customer advisors were responsible for all customer-related activities, the new organization decentralizes this responsibility to the respective point of contact (branch, online banking, call center, etc.) and shares responsibility among the involved channels. For this purpose, a channel and device management organizational unit was introduced which is responsible for the overall coordination across the different channels. This centralization of coordination competencies has enabled an integrated view on the customer and relevant customer data across multiple channels.

On the systems level, these strategic and organizational changes were implemented by means of a new system architecture: first, the front-end and back-end systems were decoupled and modularized. Typically, back-end systems in banks have a life-cycle of many years, whereas front-end applications are more dynamic. To address the latter, the bank has implemented a service-oriented frontend architecture on top of the back-end architecture. This allows the bank to act more flexibly in all customer-related processes, and to standardize products and services in order to offer them through different channels simultaneously. Second, an integration layer connects front-end and back-end applications, bundles data and organizes the collaboration by means of workflows. As a third element, the bank and its customers now work with the same applications. With the help of these applications customers may, for example, plan their financial situation in a personal finance management system and are able to switch to other channels, such as the bank's call center that processes requests concerning the same system and data.

The potentials of hybrid customer interaction as exemplified in this case are manifold. From a customer viewpoint, a frictionless experience of the interaction process without any media breaks has been observed. Further, customers are no longer required to distinguish between silo online and offline interaction points. Additionally, customers now perform more tasks in a self-service manner. From a bank's point of view, hybrid customer interaction offers potentials with respect to quality, costs and time. The bank is now able to obtain and use high-quality customer data enabled by closer integration of all channels. This data can be leveraged to strengthen the customer relationship and may help increasing cost efficiency. Additionally, the integrated interaction process with the customers allows the bank to automate and document all steps that are required for regulatory compliance. Lastly, owing to the more flexible service-oriented front-end architecture, the bank can optimize its time-to-market through faster integration of new services, such as peer-topeer payment.

\section{Definition and Research Approaches}

\subsection{Hybrid Customer Interaction}

In general, the term "customer interaction" refers to the processes between a company and its customers, i.e., the customer processes (Vandermerwe 2000). Along these processes, customers and companies share information as part of their interaction in order to jointly solve a specific customer need (Dezinger 2010).

The term "hybrid" means, inter alia, "from two different origins", "mixed" and "hermaphroditic" and thus defines several elements that are fused together and may even be hermaphroditic. The individual parts can, however be recognized in their properties, which aim at the hermaphrodite-like ones (Leimeister and Glauner 2008, p. 248). The term "hybrid" is already used in the context of so called "hybrid products". According to (Böhmann and Krcmar 2007 , p. 240) "hybrid products" are a combination of goods and services that are offered as an integrated service package to solve a specific customer problem. A hybrid 
product consists of a bundle of hardware (e.g., tablet PC, smart phone), software (e.g., apps) as well as service components (e.g., personal finance management system) and thus connects the physical and digital world (van Halen et al. 2005; Mont 2002).

Additionally, hybrid customer interaction enhances the concept of hybrid products not only by integrating these dimensions into the design of products but also into the design of holistic customer interactions along strategic, organizational and system-related aspects. With this understanding, hybrid products are components of hybrid customer interaction, since hybrid customer interaction involves the customer in the solution creation and in the provisioning process of services. Additionally, hybrid customer interaction aims at achieving smooth transitions between physical and digital forms of interaction by using hybrid products. The different interaction channels (electronic/mobile and stationary) are combined, so that the customer no longer perceives individual interaction points, but rather a consistent and holistic interaction.

\subsection{Previous Research}

Customer interaction has a long research tradition in different disciplines ranging from strategic management (e.g., marketing) over business process management (e.g., customer relationship management) to computer science (e.g., human computer interaction).

A first category falls in the area of strategic approaches, it originates from the marketing discipline and has a focus on channel management. In this area, different terms on multi, cross and omni channel management have evolved. Although these terms are all concerned with customer interaction through different distribution channels (Vinhas et al. Dezinger 2010), they emphasize different aspects of customer interaction and reflect the different stages of maturity established over time. Multi channel management $(\mathrm{MCM})$ as first maturity step is defined as [...] "the design, deployment, and evaluation of channels to enhance customer value through effective customer acquisition, retention, and development" (Neslin et al. 2006, p. 96). MCM regards channels as silos and focuses on the isolated optimization of single channels without an overall perspective. Individual channels operate separately from each other and interact independently (Heinemann 2013). In contrast to this silo type view, cross channel management (CCM) as a second maturity step focuses on customer experience across channels. This means that channels are connected to each other, so that they operate in a coordinated way and enable "channel hopping" in sequential customer processes (Heinemann 2013, p. $10 \mathrm{ff}$.). A third maturity step is omni channel management (OCM) which allows customers to simultaneously use channels. OCM focuses more closely on customer behavior than CCM. Although CCM describes the behavior of "channel hopping", the simultaneous use of channels remains outside the definition of CCM. In contrast, OCM leads to "[...] an integrated sales experience that melds the advantages of physical stores with the information-rich experience of online shopping" (Rigby 2011, p. 11). Mobile-commerce is seen as a key factor for a simultaneous interaction of different channels (Heinemann 2013; Payne and Frow 2013). Therefore, OCM uses mobile-commerce to ensure an integration of offline and online channels and finally results into "no-line systems" (Heinemann 2013). Hybrid customer interaction is based on the concept of OCM and uses channel, process and technology convergence to ensure an integrated concept of customer interaction which allows a simultaneous use of channels.

Another category of research disciplines contributing to hybrid customer interaction concentrates on organizational topics. For example, customer relationship management (CRM) aims to develop long-term customer relationships and hence controls customer contact and retention activities. To achieve this goal, CRM-systems organize and synchronize marketing, sales, and customer service along those processes (Payne and Frow 2013).

A third area of research concentrates on system-related aspects. For instance, human computer interaction (HCI) considers the improvement of how people use computers, such as tablet PCs (Pitt et al. 2011). Referring to the latter, Birch (2012) states that "the tablet is really where we will begin to see this convergence. It has PC-like real estate with mobile-like ubiquitous connectivity" (p. 1).

Hybrid customer interaction connects these different research streams across all three dimensions of strategic, organizational and system-related aspects. Hybrid customer interaction is based on OCM to ensure a simultaneous use of channels. For this, hybrid customer interaction uses hybrid products to integrate online and offline channels and utilizes channel, process and technology convergence to ensure "no-line systems" as an integrated concept of customer interaction (Heinemann 2013). The different channels are connected through tightly linked customer and CRM processes and integrated across customer, company and third party applications as well as data.

\section{Framework for Hybrid Customer Interaction}

As the case of the Swiss universal bank in Sect. 1.2 demonstrates, hybrid customer interaction needs to consider strategic, organizational and system related aspects (see Fig. 1). It also illustrates that convergence is a concept reaching beyond the mere fusion of the physical and the digital world. 
Fig. 1 Hybrid customer interaction framework

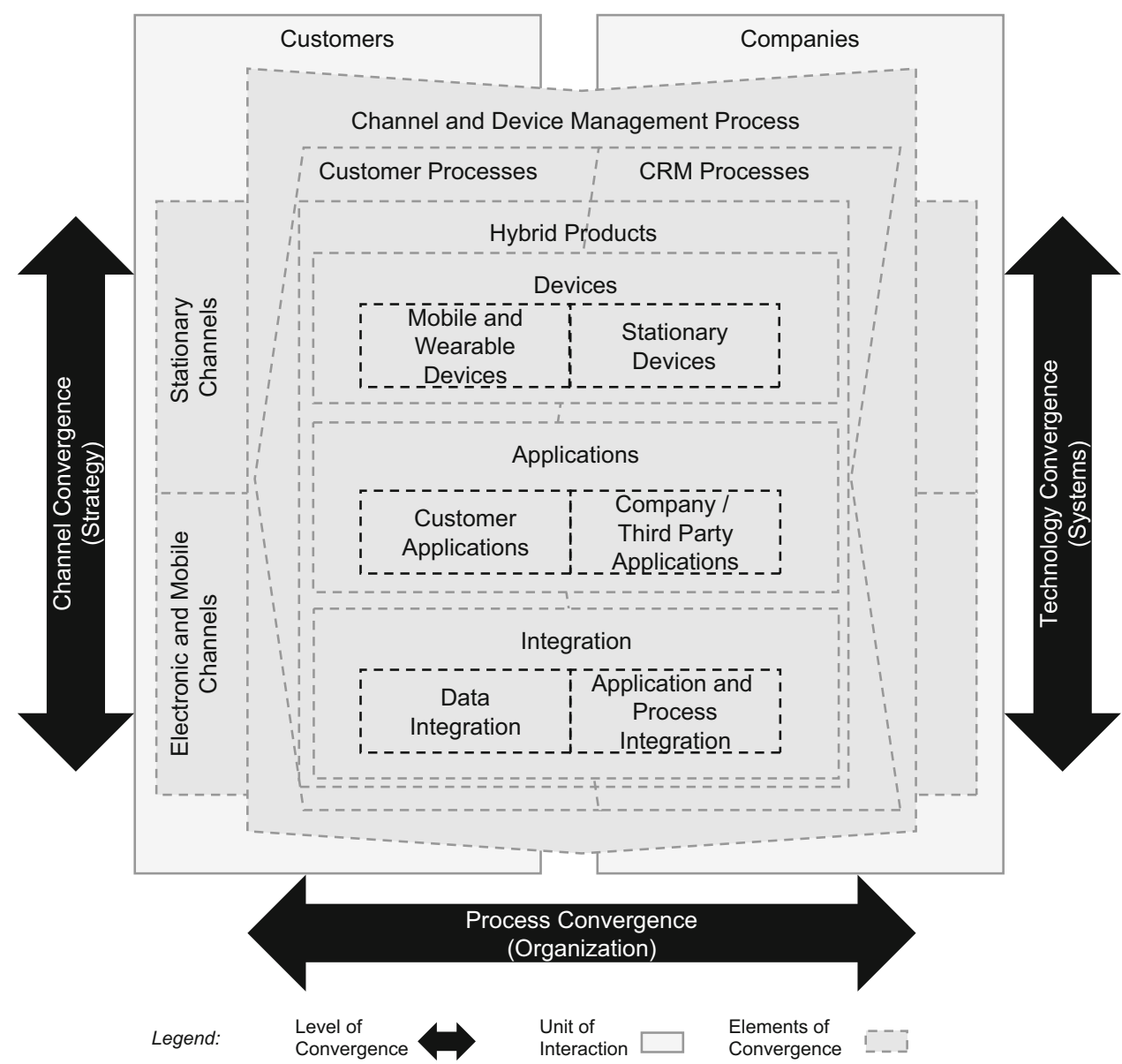

Channel convergence (strategy) concentrates on the fusion of stationary and electronic/mobile channels. In the aforementioned banking industry example, digitization and proximity to customers do not exclude each other. In the future, hybrid products are expected to extend physical proximity to emotional proximity. Thus, channel convergence means that electronic/mobile and stationary channels merge, and it connects the digital and physical elements. From a strategic perspective, hybrid customer interaction needs to consider different aspects. First, all channels have to be positioned as equal customer interaction points in order to ensure a "no-line system". Instead of providing single services exclusively via one channel (e.g., advisory services only in branches), the services have to be designed across different channels (e.g., mobile channels and the physical customer advisor). Second, the channels need to be integrated with each other and even with external service providers. Surveys (e.g., Sachse et al. 2012) indicate that customers already intensively use non-bank services. Third, digitization paves the way for customers to conduct more services (or parts thereof) on their own. New banking applications, for example, allow customers not only to perform self-service transactions and support processes, but also advisory processes based on self-profiling and personal financial management systems. Another example, which illustrates that customer integration requires new services, are video equipped self-service ATMs. Here, traditional ATMs are enhanced with video functionalities to interact with advisors in a remote call center.

Process convergence (organization) means that customer processes and companies' CRM processes are integrated. From an organizational perspective, two aspects are seen as key factors for hybrid customer interaction. First, due to the closer involvement of the customer in companyrelated processes, the different points of interaction (e.g., mobile and branches) must be identified and integrated consistently. To ensure such a hybrid customer interaction, banks need to connect CRM processes with customer processes in a standardized way. By means of an integrated CRM, customers have the opportunity to change their interaction point within their customer process as often as they desire, while the information about them is available and remains uniform across all interaction points. This is done under the assumption that each process step is digitized and documented in real-time. 
Second, an overall channel and device management process is required. This process actively coordinates all points of contact with the customer and shows options for the design of services and the selection of channels. It supports strategic and operational orientation towards the customer (which services are prioritized at which contact points) and ensures the connection to the network management.

Technology convergence (system) means that single devices and single applications merge. This implies that each service can be used with any stationary, mobile or wearable device. For this, hybrid customer interaction relies on integrated devices and applications. In order to facilitate this integration, an open architecture is needed which meets requirements such as scalability, management of third party suppliers, cross-uniform data management across all interaction points, as well as being web-enabled, standardized and modularized. Three factors have to be considered on the system level.

First, to implement a hybrid customer interaction, companies need to decouple their back-end applications from their front-end applications, e.g., by using serviceoriented front-end architectures (as described in the introductory case example). In particular, the back-end system should be modularized and the integration layer (interaction engine to handle data and workflows) combines the front-end and the back-end. Additionally, front-end applications are implemented as a collection of web services in the sense of an app framework. Currently, a broad variety of new application categories in customer-related processes is emerging. These solutions have different requirements regarding user interface and interaction (e.g., gesture and voice interaction) than back-end applications. In particular, systems for social CRM (Alt and Reinhold 2012), hybrid customer interaction applications, and mobile app stores are required.

Second, companies need to implement centralized hybrid customer interaction applications. These applications integrate customer applications, companies' front-end applications and back-end applications as well as third party services and serve as a centralized data and process integration layer.

Third, an increasing number of devices and device types used by customers and employees require new approaches of service design and management. For example, an application for personal financial planning used on a customer's tablet PC has to be designed in a different way than if the same application is used on a desktop computer and this might even be different from one that is used in a branch on a tablet PC. If functions are available on smart phones, interactive glasses or other wearable devices, differing service designs might apply to the same context.

\section{Implications for Further Research}

Even though the topic of customer interaction has been discussed in literature for several years, new and more comprehensive forms of interaction opportunities arise constantly. Companies need to adapt to these developments. The topic of mobile-commerce is of particular importance in this discussion, as it allows simultaneous interaction at any point most consistently, namely the interaction with the smart phone on the spot (Heinemann 2013). Reflecting these developments, this paper outlines the main aspects of an integrated hybrid customer interaction based on convergence aspects. First, customer interaction merges electronic/mobile and stationary channels (channel convergence). Second, customers' and companies' processes are becoming more integrated (process convergence). Third, each device may be used with every service and application (technology convergence).

To establish hybrid customer interaction, companies need to ensure a seamless integration of relevant interaction points with the customer. The physical proximity previously achieved through physical branches is complemented by an emotional proximity via digitization. By offering hybrid products, the limitations of siloed interaction points are overcome and individual interaction points merge, so that the customer perceives the interaction of the online and offline world as a "no-line system".

In the future, this could lead to two major developments. First, new ecosystems, formed by the outside-in driven configuration of value chains and the convergence of different channels towards the customer, could emerge. An example is Apple with its recently launched mobile payment system Apple Pay, which relies on collaboration with credit card companies and banks. It allows customers to pay with different cards from different banks via a single app. Second, if customers are enabled to configure their services across company borders, this has a significant impact on customer interaction and leads to the development of new customer-oriented infrastructures (Alt and Puschmann 2012). These infrastructures tie up to the concept of electronic market platforms. In banking, for example, these electronic markets are well established in business-to-business processes, such as stock exchanges, but they have not yet diffused into business-to-customer processes. An example could be an infrastructure which allows customers to use different mobile apps from different financial service providers that are interoperable regarding processes and data. This would enable customers to plan their financial goals across different services from different providers.

In summary, hybrid customer interaction is expected to gain further importance driven by the developments in IT towards further convergence of technologies and electronic 
services. The concept emphasizes the need to align strategy, organization and systems across company borders and to closely integrate customers with processes and systems of service providers. This offers a wide array for future research, such as the customer-oriented design of products and services and their configuration. Further fields are customer-centric application architectures and hybrid customer interaction applications. Finally, this raises the question which forms of hybrid customer interaction will gain widespread acceptance and eventually pay off for the company.

As long as the convergence of the digital and the physical world continues to increase, hybrid customer interaction will gain importance as a new field of research and practice.

\section{References}

Alt R, Puschmann T (2012) The rise of customer-oriented banking: electronic markets are paving the way for change in the financial industry. electron mark 22(4):203-215

Alt R, Reinhold O (2012) Social customer relationship management (social CRM) - application and technology. Bus Inf Syst Eng 4(5):287-291

Bettiga D, Boaretto A, Che S (2013) Exploring media convergence: evidence from Italy. Int J Eng. Bus Manag 5(1):1-9

Birch R (2012) Study: channel convergence "coming fast”. Credit Union Journal 16(14):3

Böhmann T, Krcmar H (2007) Hybride Produkte: Merkmale und Herausforderungen. In: Bruhn M, Stauss B (eds) Wertschöpfungsprozesse bei Dienstleistungen - Forum Dienstleistungsmanagement. Gabler, Wiesbaden, pp 239-258

Brenner W, Österle H, Petrie C, Uebernickel F, Winter R, Karagiannis D, Kolbe L, Krüger J, Leifer L, Lamberti H-J, Leimeister JM,
Schwabe G, Zarnekow R (2014) User, use \& utility research. Bus Inf Syst Eng 6(1):55-61

Dezinger F (2010) Kundeninteraktionskompetenz in Industriegütermärkten - Eine empirische Studie zur Interaktions- und Lernorientierung. Gabler, Wiesbaden

Heinemann G (2013) No-Line-Systeme als Betriebsform der Zukunft - Höchste Evolutionsstufe im Multi-Channeling. Springer, Heidelberg

Leimeister JM, Glauner C (2008) Hybride Produkte - Einordnung und Herausforderungen für die Wirtschaftsinformatik. WIRTSCHAFTSINFORMATIK 50(3):248-251

Leimeister JM, Österle H, Alter S (2014) Preface special issue on "Digital services for consumers". Electron Mark 24(4):1-4

Mont O (2002) Clarifying the concept of product-service system. J Clean Prod 10(3):237-245

Neslin S, Shankar V (2009) Key issues in multichannel customer management: current knowledge and future directions. J Interact Mark 23(1):70-81

Neslin SA, Gerwal D, Leghorn R, Shankar V, Teerling ML, Thomas JS, Verhoef PC (2006) Challenges and opportunities in multichannel customer management. J Serv Res 9(2):95-112

Nueesch R, Puschmann T, Alt R (2014) Realizing value from tabletsupported customer advisory: cases from the banking industry. In: Proceedings of 27th Bled eConference Slovenia, pp 292-305

Payne A, Frow P (2013) A strategic framework for customer relationship management. J Marketing 69(4):167-176

Pitt L, Berthon P, Robson K (2011) Deciding when to use tablets for business applications. MIS Q Exec 10(3):133-139

Rigby D (2011) The future of shopping. Harvard Business Review December 2011

Sachse S, Puschmann T, Alt R (2012) Towards customer-oriented electronic markets - a survey among digital natives in the financial industry. In: Proceedings of 25th Bled eConference, Slovenia, pp 333-354

Van Halen C, Vezzoli C, Wimmer R (2005) Methodology for product service system innovation: how to develop clean, clever and competitive strategies in companies. Van Gorcum, Assen

Vandermerwe S (2000) How increasing value to customers improves business results. Sloan Manag Rev 42(1):27-37 